\title{
Can Lactobacillus sp. Prevent Alone Recurrent Non- Complicated Urinary Tract Infection?
}

\author{
Carmen Antonela Bejinariu ${ }^{1,2}$, Luminița-Smaranda Iancu ${ }^{1,3}$, Eduard Vasile Nastase ${ }^{* 1,2}$, Cătălina \\ Luncă ${ }^{1,3}$ and Olivia Simona Dorneanu ${ }^{1,2}$ \\ 1"Grigore T. Popa" University of Medicine and Pharmacy, Iași, Romania \\ ${ }^{2}$ "Sf. Parascheva" Hospital of Infectious Diseases, Iași, Romania \\ ${ }^{3}$ Regional Center of Public Health, Iași, Romania \\ *Corresponding author: Eduard Vasile Nastase, Grigore T. Popa” University of Medicine and Pharmacy, "Sf. Parascheva” Hospital of \\ Infectious Diseases, Iași, Romania
}

\begin{tabular}{|c|c|}
\hline ARTICLE INFO & ABSTRACT \\
\hline Received: 蔧 March 06, 2021 & $\begin{array}{l}\text { As microbiologists or clinical doctors, in daily practice, we assist to cases of recurrent } \\
\text { urinary tract infection in women. They appear despite a correct antibiotic regimen }\end{array}$ \\
\hline Published: 㗀 March 24, 2021 & $\begin{array}{l}\text { recommended by the physicians and correctly followed by the patients. In this mini } \\
\text { review, we set to investigate the existing medical literature in order to find if Lactobacillus }\end{array}$ \\
\hline
\end{tabular}

Citation: Carmen Antonela Bejinariu, Luminița-Smaranda Iancu, Eduard Vasile Nastase, Cătălina Luncă, Olivia Simona Dorneanu. Can Lactobacillus sp. Prevent Alone Recurrent Non-Complicated Urinary Tract Infection?. Biomed J Sci \& Tech Res 34(4)-2021. BJSTR. MS.ID.005593.

Keywords: Lactobacillus sp.; Prevention; Urinary Tract Infection; Recurrent Urinary Tract Infection

Abbreviations: UTI: Urinary Tract Infection; RUTI: Recurrent Urinary Tract Infection

\section{Mini Review}

At least once in their lifetime, no matter what age, approximately $50 \%$ of women are confronting with non-complicated UTI, and $20-30 \%$ of them are facing recurrences [1]. RUTI is commonly defined as at least two episodes of specific symptoms associated with pyuria or positive bacterial culture in the past six months or three infections in the last twelve months. A major problem the physicians have to deal with is the antimicrobial resistance as consequence of excessive use of antibiotics in human and veterinary medicine, meaning that the effective antibiotics panel is diminishing [2]. The literature we have examined correlates the already known relation between UTI, RUTI, and microbiological charge of perianal, perineal, vulvovaginal and periurethral areas. Starting from perianal area, the uropathogenic bacteria are carriedout to the perineal zone, and periurethral tissues, possibly causing vaginosis, vulvovaginitis, and/or cystitis. This carriage is related to many factors, such as incorrect behavior regarding intimate hygiene, the sexual habits, and the use of spermicides $[3,4]$. The role of lactobacilli in the maintenance of vaginal health was first recognized by Döederlein in the late $18^{\text {th }}$ century, the concept of administering exogenous Lactobacillus for maintaining optimal vaginal microflora being more than a century old.

Vaginal lactobacilli protect the female urogenital tract from pathogen colonization, contributing to the prevention of genitourinary tract infection. Many studies have been published describing the relationships between bacterial vaginosis and lactobacilli [5]. The host predisposing and genetic factors have been proven to alter vaginal microbial composition, the disrupted vaginal ecosystem often resulting in a disease state and symptomatic vaginitis. Meanwhile, Lactobacillus have shown to possess potential health benefits in immunomodulation and restoration of healthy microflora in gut and vagina [6]. The Lactobacillus-dominated vaginal flora in premenopausal women impedes colonization with uropathogens due to competitive exclusion and maintaining low vaginal $\mathrm{pH}$ [7]. While the concept of probiotics seems to be simple 
in some ways, the critical issues include the selection of the optimal strains, verification of the necessity for, and mechanisms of, certain factors in the interference with pathogens and clinical proof that there is merit to the theory. Lactobacilli produce hydrogen peroxide, increasingly recognized as essential components of a healthy microflora environment, also being a toxic compound to many microorganisms at concentrations that are typical in the vaginal fluid, providing an intrinsic protective mechanism in the vagina [8].

\section{Results}

Studies using Lactobacillus-containing products such as yogurt have been largely unsuccessful in demonstrating successful colonization with the exogenous strain and influencing clinical outcomes related to bacterial vaginosis [9]. However, it has been reported that Lactobacillus vaginal capsules are effective in treating bacterial vaginosis and in reestablishing a Lactobacilluspredominant flora [10]. Randomized controlled trials have assessed the therapeutic efficacy and tolerability of Lactobacillus in UTI. Relevant randomized controlled published trials reported a beneficial effect for probiotics involving treatment of UTI [6]. But there are also studies that found no therapeutic effect of lactobacilli in the treatment or prophylaxis of UTI, few attempting to validate the probiotic dosing strategy by obtaining quantitative evidence of local colonization with lactobacilli, with sufficient power to detect treatment effects, and fewer addressing the stability of the probiotic product. Therefore, the results of studies of lactobacilli for the prophylaxis of UTI remain generally inconclusive as result of small sample sizes, product stability, strain-specific effects, and dosing strategies [11]. Different types of Lactobacillus were administered either as oral capsules, drinks, or yoghurt, or in vaginal suppositories, tampons, or douches.

Treatment durations varied and trial controls were active, placebo, or no treatment, aiming the reduction in symptomatic UTI. For the therapy assessment of UTI, there are double-blind trials (with one placebo-controlled), follow-up ranging from six months to one year. Therefore, one out of four trials reported a $73 \%$ reduction in episodes of recurrent UTI compared with the previous year in both studied groups; the other three studies found no beneficial effects of Lactobacillus-containing probiotics on recurrence of UTI. Also, five trials reported that Lactobacillus therapy was well tolerated based on the absence of discontinuations and either an absence of adverse events or a similar number of adverse events between groups [5]. It is proved that most UTIs are caused by intestinal bacteria that ascend through the urethra to the bladder and, sometimes, kidneys [12]. Specific lactobacilli strains can interfere with the adherence, growth, and colonization with uropathogenic bacteria, reducing the risk of ascent into the bladder [13]. There are only a few studies characterizing the vaginal Lactobacillus species in healthy women of reproductive age in India. More studies in India are warranted as the species distribution in Indian women may be different.
This would raise the question on the necessity in a probiotic of a single species or a balanced mixture depending on the local flora [14].

\section{Discussion}

Currently, the available literature indicates no strong evidence about efficiency of using lactobacilli as unique therapy in prevention of RUTI, but considering their benefits for the gut, perianal, perivaginal and periurethral microbiome, they may be used according to the producers recommendations together with other nonspecific measures: a correct hygiene habit, avoiding use of spermicides and above all, limitation of the antibiotic use to only the cases when the bacterial causes are confirmed by microbiology tests and the recommendations are made according to the results of the susceptibility testing.

\section{Conclusion}

Considering their so many beneficial properties, lactobacilli are promising as adjuvant therapy for vaginal infection to prevent UTI and RUTI. There is a need of larger randomized trials, with welltargeted patients and methods, aiming to find a non-antibiotic prophylaxis for UTI and RUTI.

\section{References}

1. Florian Wagenlehner, Björn Wullt, Stefania Ballarini, Daniel Zingg, Kurt G Naber (2018) Social and economic burden of recurrent urinary tract infections and quality of life: A patient web-based study (GESPRIT). Expert Review of Pharmacoeconomics \& Outcomes Research 18(1): 107-117.

2. Néha Sihra, Anna Goodman, Rhana Zakri, Arun Sahai, Sachin Malde (2018) Nonantibiotic prevention and management of recurrent urinary tract infection. Nat Rev Urol 15(12): 750-776.

3. José Antonio Ortega Martell, Kurt G Naber, Jorge Milhem Haddad, José Tirán Saucedo, Jesús Alfonso Godínez Burgos (2019) Prevention of recurrent urinary tract infections: Bridging the gap between clinical practice and guidelines in Latin America. Ther Adv Urol 11(1): 29-40.

4. Ilya Gorbachinsky, Robert Sherertz, Gregory Russell, L Spencer Krane, Steve J Hodges (2014) Altered perineal microbiome is associated with vulvovaginitis and urinary tract infection in preadolescent girls. Ther Adv Urol 6(6): 224-229.

5. Ann E Stapleton (2016) The Vaginal Microbiota and Urinary Tract Infection. Microbiol Spectr 4(6): 10.

6. Wallace Jeng Yang Chee, Shu Yih Chew, Leslie Thian Lung Than (2020) Vaginal microbiota and the potential of Lactobacillus derivatives in maintaining vaginal health. Microb Cell Fact 19(1): 203.

7. Gupta V, Nag D, Garg P (2017) Recurrent urinary tract infections in women: How promising is the use of probiotics? Indian J Med Microbiol 35(3): 347-354.

8. Heidari F, Abbaszadeh S, Mirak SEM (2017) Evaluation Effect of Combination Probiotics and Antibiotics in the Prevention of Recurrent Urinary Tract Infection (UTI) in Women. Biomed Pharmacol J 10(2).

9. Lee NK, Kim SY, Han KJ, Eom SJ, Paik HD (2014) Probiotic potential of Lactobacillus strains with anti-allergic effects from kimchi for yogurt starters. LWT-Food Sci Technol 58(1): 130-134.

10. Lakritz JR, Poutahidis T, Levkovich T, Varian BJ, Ibrahim YM, et al. (2014) Beneficial bacteria stimulate host immune cells to counteract dietary 
and genetic predisposition to mammary cancer in mice. Int J Cancer 135 529-540.

11. Robert Barrons, Dan Tassone (2008) Use of Lactobacillus probiotics for bacterial genitourinary infections in women: A review. Clin Ther 30(3): 453-468.

12. Al Badr A, Al Shaikh G (2013) Recurrent urinary tract infections management in women - a review. Sultan Qaboos Univ Med J 13(03): 359-367.

\section{ISSN: 2574-1241}

DOI: $10.26717 /$ BJSTR.2021.34.005593

Eduard Vasile Nastase. Biomed J Sci \& Tech Res

This work is licensed under Creative Commons Attribution 4.0 License

Submission Link: https://biomedres.us/submit-manuscript.php
13. Gupta K, Stapleton AE, Hooton T M, Roberts PL, Fennell CL, et al. (1998) Inverse association of H2O2-producing Lactobacilli and vaginal Escherichia coli colonization in women with recurrent urinary tract infections. J Infect Dis 178(02): 446-450.

14. Lipika Singhal, Varsha Gupta, Menal Gupta, Poonam Goel, Jagdish Chander (2020) Identification and Sensitivity of Vaginal and Probiotic Lactobacillus species to Urinary Antibiotics. J Lab Physicians 12(2): 111114 .

$\begin{array}{ll}\text { BIOMEDICAL } & \text { Assets of Publishing with us } \\ \text { RESEARCHES } & \text { - Global archiving of articles } \\ \text { - Immediate, unrestricted online access }\end{array}$

